\title{
Errata Sheet \\ For \\ Analog Integrated Circuits and Signal Processing
}

In Volume 3 Issue 1 of Analog Integrated Circuits and Signal Processing "Symbolic Analysis of Large-Scale Networks Using a Hierarchical Signal Flowgraph Approach" by M.M. Hassoun and K.S. McCarville (page 42), partial reference numbers were inadvertently left off the reference listing. The corrected reference listing is below:

9. M. M. Hassoun, "Symbolic analysis of large-scale networks," Ph.D. dissertation, Purdue University Engineering Library, West Lafayette, IN, 1988.

10. W.-K. Chen, Passive and Active Filters Theory and Implementations, Wiley: New York, 1986.

11. L.O. Chua and P.M. Lin, Computer Aided Analysis of Electronic Circuits-Algorithms and Computational Techniques, PrenticeHall: Englewood Cliffs, NJ, 1975.

12. F:R. Adby, "Tree enumeration from the incidence matrix," Int. J. Elec. Eng. Educ., Vol. 24, pp. 183-187, 1987.

13. G. Gielen and W. Sansen, Symbolic Analysis for Automated Design of Analog Integrated Circuits, Kluwer: Boston, 1991.

14. M. M. Hassoun, "Hierarchical symbolic analysis of large-scale systems using a Mason's signal flowgraph model," in Proc. IEEE Int. Symp. on Circuits and Sys., pp. 802-805, 1991.

15. A. Konczykowska and M. Bon, "Symbolic simulation for efficient repetitive analysis and artificial intelligence techniques in CAD," in Proc IEEE Int. Symp. Circuits Sys., pp. 802-805, 1989.

16. P.-M. Lin, Symbolic Network Analysis, Elsevier: Amsterdam, Netherlands, 1991.
17. S.J. Mason, "Feedback theory-some properties of signal flowgraphs," Proc. IRE, Vol. 41, pp. 1144-1156, 1953.

18. S.J. Mason, "Feedback theory-further properties of signal flowgraphs," in Proc. IRE, Vol. 44, pp. 920-926, 1956.

19. R.R. Mielke, "A new signal flowgraph formulation of symbolic network functions," IEEE Trans. Circuits Sys., Vol. CAS-25, pp. 334-340, 1978.

20. M. Sagawa and H. Kitazawa, "Symbolic network analysis of linear networks using parameter extraction proc.," Trans. IECE Japan, Vol. E 60, No. 8, Abs, p. 414, 1980.

21. K. Singhal and J. Vlach, "Generation of immetance functions in symbolic form for lumped distributed active networks," IEEE Trans. Circuits Sys., Vol. 21, pp. 57-67, 1974.

22. K. Singhal and J. Vlach, "Symbolic analysis of analog and digital circuits," IEEE Trans. Circuits Sys., Vol. 24, pp. 598-609, 1977.

23. R. Sommer, "EASY-an experimental analog design system framework," Int. Workshop Sym. Methods Appl. Circuit Design, 1991.

24. J.A. Starzyk and A. Konczykowska, "Flowgraph analysis of large electronic networks," IEEE Trans. Circuits Sys., Vol. CAS-33, pp. 302-315, 1986.

Also in Volume 3 Issue 1 "Formula Approximation for Flat and Hierarchical Symbolic Analysis" by F.V. Fernández, A. Rodríguez-Vásquez, J.D. Martin and J.L. Huertas (page 58), the bio photos for Angel Rodriquez-Vázquez and José L. Huertas were reversed.

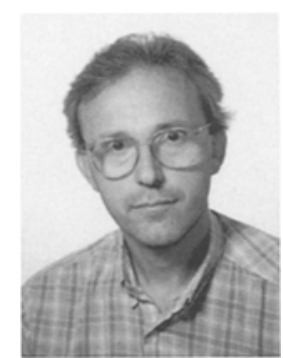

Angel Rodríquez-Vázques

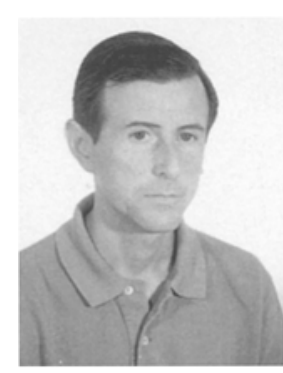

José L. Huertas 


\section{Errata Sheet \\ For \\ Analog Integrated Circuits and Signal Processing}

In Volume 3 Issue 2 of Analog Integrated Circuits and Signal Processing "Nonlinearity-Induced Distortion of the Transfer Function Shape in High-Order OTA-C-Filters" by S. Szczepanski and R. Schaumann (page 147), copy for figure 2 was omitted in printing. The figure is reproduced below:

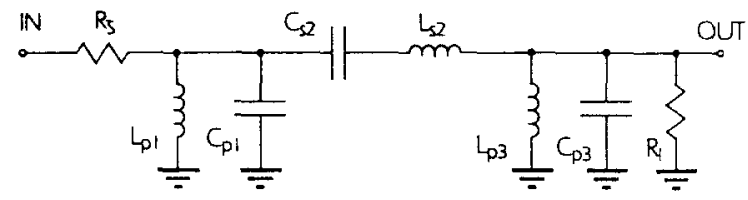

Fig. 2. Sixth-order $L C$ bandpass ladder. 